\title{
THE ROLE OF SURGERY IN TREATMENT OF PINEAL GERMINOMA: A CASE REPORT
}

\author{
Mirsad HODŽIĆ ${ }^{1}$, Pierre KEHRLI², Selma JAKUPOVIĆ ${ }^{1}$, Zlatko ERCEGOVIĆ ${ }^{1}$, \\ Elmir ČIČKUŠIĆ̉
}

\author{
${ }^{1}$ Department of Neurosurgery and \\ ${ }^{3}$ Department of Pathology University \\ Clinical Hospital Tuzla, Bosnia and \\ Herzegovina, ${ }^{2}$ Service de Neurochirurgie \\ Hopital Hautepierre Strasbourg, France \\ Corresponding author: \\ Mirsad Hodžić \\ Department of Neurosurgery \\ University Clinical Hospital Tuzla \\ Tuzla, Bosnia and Herzegovina \\ mirsad.hodzic2@ukctuzla.ba \\ Tel.: + 38761100145 \\ Fax.: + 38735303249
}

Received: December 17, 2013

Accepted: January 20, 2014

Copyright (C) 2014 by University Clinical Hospital Tuzla. E-mail for permission to publish: paediatricstoday@ukctuzla.ba

\begin{abstract}
Objective - The aim of this case report is to present the results of surgical treatment of a patient with the pineal germinoma. Case report - A 12-year-old patient presented with two months history of headache, nausea, and vomiting, following by neuro-ophthalmologic disturbances (Parinaud syndrome). Computed tomography of the head showed a $3 \mathrm{~cm}$ mass in the pineal region, followed by obstructive hydrocephalus, and magnetic resonance imaging showed a pineal gland lesion with heterogeneous enhancement on contrast studies, with surrounding peritumoral edema, suggesting pineal germinoma. The patient underwent surgery to place a ventricular-peritoneal shunt, and second surgery using the occipital interhemispheric transtentorial approach to remove the tumor totally. Conclusion - Pineal germinomas that compress adjacent structures result in a typical clinical syndrome with endocrine malfunction, hydrocephalus or neuro-ophthalmological disturbances. A multimodality approach, including chemotherapy, radiotherapy and surgery, can offer excellent chances of free survival, and even cure.
\end{abstract}

Kay words: Pineal germinoma - Surgery.

\section{Introduction}

The term germinoma most often refers to a tumor in the brain that has histology identical to two other tumors: dysgerminoma in the ovary and seminoma in the testis (1). Germinomas are the most common germ cell tumors (GCTs) and account for $41-50 \%$ of all GCTs. Intracranial germinomas occur in 0.7 per million children. These tumors are gonadal neoplasms but sometimes occur extragonadally in the midline structures of the retroperitoneum and the mediastinum (2).

The incidence of pineal germinoma varies from 0.4 to $3.4 \%$ in the West, whilst in Japan it is 5 to 8 times more frequent $(3,4)$. They are commonly diagnosed in the first and second decade of life, with a median age of diagnoses of 10-12 years of age $(4,5)$. Tumor removal can offer the best prognosis for the patient.

The aim of this study is to present a case of pineal germinoma that was treated surgically.

\section{Case report}

A 12-year-old patient, with no significant past medical history, presented with two months history of headache, nausea, and vomiting, following by a syndrome of vertical gaze 


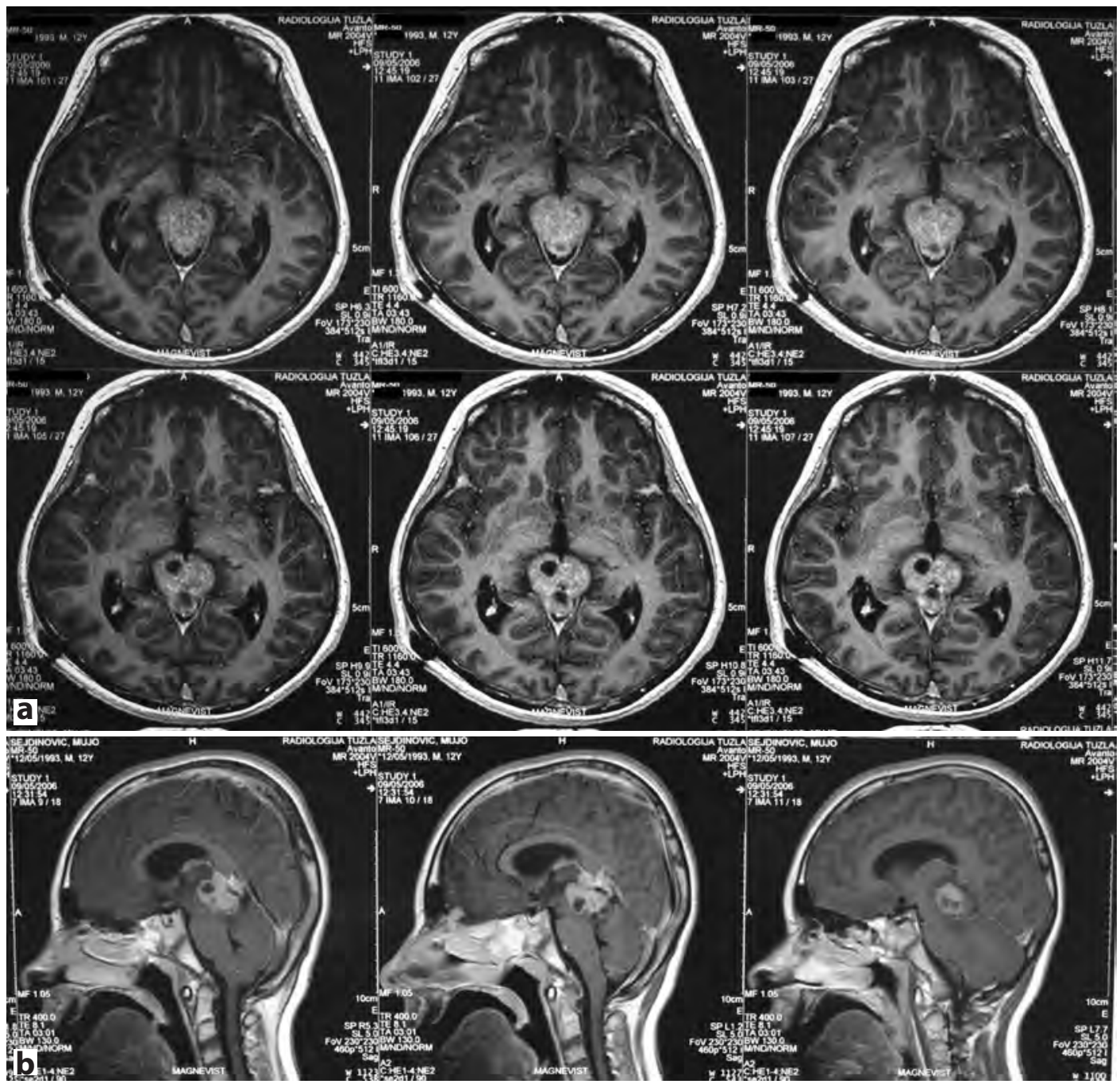

Fig. 1 Preoperative magnetic resonance imaging. (a) Axial, and (b) sagittal postcontrast T1W images depict a $3 \times 3 \mathrm{~cm}$ space-occupying lesion in the pineal region.
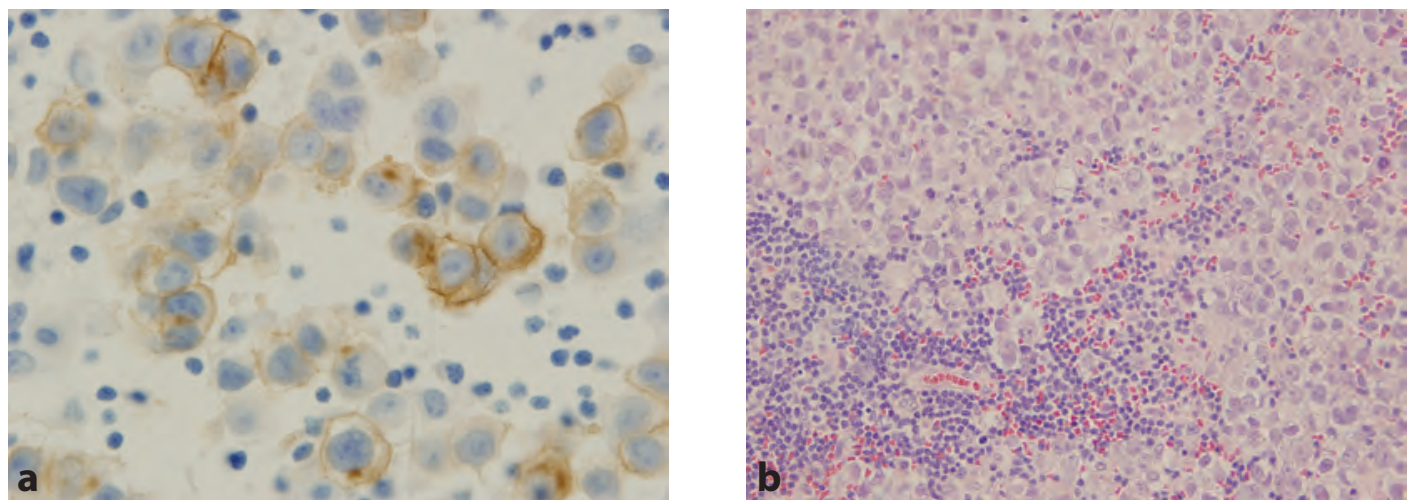

Fig. 2 Histopathological examination of the surgical specimen. Pineal germinoma. 

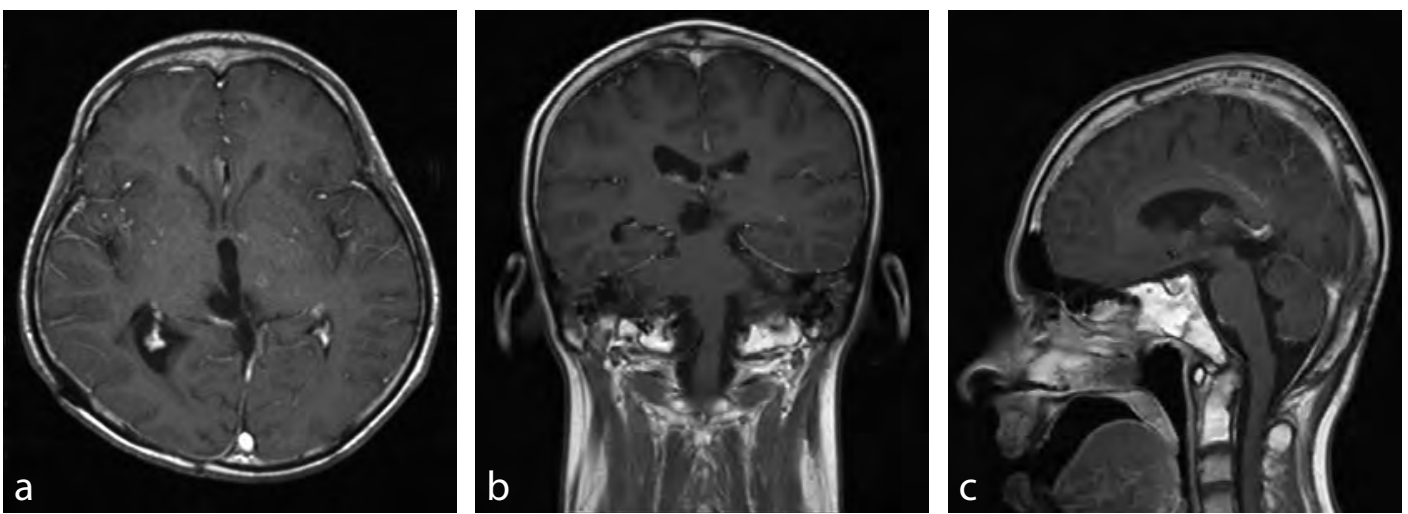

Fig. 3 Postoperative magnetic resonance imaging six years after surgery. (a) Axial, (b) coronal, and (c) sagittal postcontrast $T 1 \mathrm{~W}$ images.

palsy, associated with abducens nerve paresis, convergence spasm and nystagmus (Parinaud syndrome). The rest of his neurological exam showed a motor impairment with ataxia and dysmetria. The chest, heart, and abdominal exams were unremarkable.

Imaging. Computed tomography (CT) of the head showed a $3 \mathrm{~cm}$ high-density lesion with homogenous enhancement in the region of the pineal gland. Subsequent magnetic resonance imaging (MRI) of the brain (Fig. 1) showed a $3 \mathrm{~cm}$ isointense pineal gland lesion on $\mathrm{T} 1$ and $\mathrm{T} 2$ sequences, with heterogeneous enhancement on contrast studies with surrounding peritumoral edema, suggesting pineal germinoma.

Surgical procedures. The patient first underwent surgery to place a ventriculoperitoneal (VP) shunt to relieve the increased intracranial pressure. The second surgery was performed using the occipital interhemispheric transtentorial approach and the tumor was totally removed. Result. The patient's symptoms resolved after surgery and he stayed neurologically intact. Postoperative CT showed no remnant mass in the pineal region. Histopathological examination of the surgical specimen was characterized by a typical type cell pattern tumor, composed of germinoma cells mixed with lymphocytic infiltration. The lymphocytic infiltration was around the vascular stroma and the lympho- cytes were T-lymphocytes. Immunocytochemistry showed that the tumor cells were positive for placental alkaline phosphatase (PLAP), and negative for alpha-fetoprotein (AFP) and beta-human chorionic gonadotropin (BHCG) (Fig. 2). The final diagnosis was germinoma. Since the tumor was totally removed, the patient was not treated with radiotherapy. The patient was followed-up by MRI for six years, with no evidence of recurrence (Fig. 3).

\section{Discussion}

Intracranial germinoma occurs in 0.7 per million children (6). As with other GCTs occurring outside the gonads, the most common location of intracranial germinoma is on or near the midline, often in the pineal or suprasellar areas; in $5-10 \%$ of patients the germinoma is in both areas. Like other GCTs, they may occur in other parts of the brain. Within the brain, this tumor is most common in the hypothalamic or hypophiseal regions. In the thalamus and basal ganglia, germinoma is the most common GCT (7).

The clinical presentation of pineal germinoma can be a consequence of obstructive hydrocephalus, neuro-ophtalmologic disturbances (Parinaud syndrome), and endocrine disorder. One of the patient's clinical features is hypothalamic-pituitary axis dysfunction 
(8). Endocrinological manifestations, including diabetes insipidus, delayed gonadal function, and precocious puberty, are commonly seen in patients with pineal germinomas ( 9 , $10,11)$. In our case the patient was followed by the pediatrician before and after surgery and there was no hypothalamic-pituitary axis or endocrinological disorder noticed.

The parinaud syndrome noticed in this patient is an important clinical presentation of pineal germinomas (12). Parinaud syndrome is caused by direct compression of the quadrigeminal plate, which interrupts the neurons that link the cerebral cortex, the superior colliculi, and the nucleus oculomotorius. The triad of Parinaud syndrome includes: upward gaze palsy, dissociation of pupillary response to light and accommodation and failure of ocular convergence.

Increased intracranial pressure (ICP) in this patient was present due to obstruction of cerebrospinal fluid flow by compression of the aqueduct by the pineal germinoma, causing obstructive hydrocephalus. Raised ICP may cause headaches, projectile vomiting, and papilledema (13), as happened in this case. Hydrocephalus is a serious complication of pineal region tumors and has to be managed appropriately. Since there was no neuroendoscopy, we placed a ventriculoperitoneal shunt as a first step to relieve the increased intracranial pressure. Neurosurgeons have the ability to perform endoscopic third ventriculostomy safely in patients with hydrocephalus from pineal region germinomas (9). Ventriculostomy is considered a good alternative to VP shunt to relieve the hydrocephalus, and it does not carry the risk of possible peritoneal metastasis in the future (14).

CT and MRI are the most reliable imaging methods for pineal germinoma. Even with advances in the field of neuroimaging, it is very difficult to distinguish between pineal germinomas and gliomas or metastases on the basis of imaging alone. PLAP, human chori- onic gonadotrophin HCG and AFP are useful tumor markers for central nervous system germinomas $(7,15)$. For technical reasons we were not able to obtain tumor markers in this case. Tumor markers are not specific enough to establish the difference in the histological types of germ cell tumors (16).

Pineal germinomas are a rare occurrence, and treatment protocols vary from centre to centre (17). Clinicians currently depend on tissue biopsy to make an accurate diagnosis in the treatment algorithm of pineal germinomas. Germ cell tumors necessitate a multimodality approach including chemotherapy, radiotherapy and surgery. Pure germinoma can be cured without ablative surgery with chemotherapy and radiotherapy (18). Since this tumor is exquisitely radiosensitive, $90 \%$ of patients with pure intracranial germinomas can be treated successfully by radiation therapy (19). There are two isolated case reports of spontaneous regression of pineal germinomas that have been attributed to the immune response of the patient. The cases have been linked to similar cases of testicular seminomas (20).

Our patient underwent ventriculoperitoneal shunt placement to relieve intracranial pressure and the tumor was totally removed using the occipital interhemispheric transtentorial approach as the second step in the treatment of this patient. Initial follow-up exams after surgical removal were performed at short intervals, with MRI scans obtained every 6 months for 3 years after diagnosis, and then at 1-year intervals. After six years of patient follow-up there has been no recurrence of the tumor and the patient is neurologically stable.

\section{Conclusion}

Pineal germinomas that compress adjacent structures result in a typical clinical syndrome, with endocrine malfunction, hydrocephalus or neuro- ophthalmological distur- 
bances. Untreated, hydrocephalus may lead progressively to lethargy, obtundation, and death. A multimodality approach, including chemotherapy, radiotherapy and surgery, can offer excellent chances of free survival, and even cure. Clinical remission is defined by the normalization of tumor markers and the absence of residual tumor.

Authors' contributions: Conception and design: $\mathrm{MH}$; Acquisition, analysis and interpretation of data: $\mathrm{MH}$, PK, EČ; Drafting the article MH, SJ, ZE; Revising it critically for important intellectual content: $\mathrm{MH}, \mathrm{PK}$.

Conflict of interest: The authors declare that they have no conflict of interest.

\section{References}

1. Shim KW, Kim DS, Choi JU. Mixed or metachronous germ-cell tumor? Childs Nerv Syst. 2007;23:713-8.

2. Aker FV, Berkman ZM, Aydingöz I, Hakan T, Toksoy $\mathrm{G}$. Pineal germinoma associated with multiple congenital melanocytic nevi: a unique presentation. Neuropathology 2005;25:336-40.

3. Packer RJ, Cohen BH, Cooney K. Intracranial germ cell tumors. Oncologist. 2000;5:312-20.

4. Lee L, Saran F, Hargrave D, Bodi I, Bassi S, Hortobagyi T. Germinoma with synchronous lesions in the pineal and suprasellar regions. Childs Nerv Syst. 2006;22-8.

5. Jennings MT, Gelman R, Hochberg F. Intracranial germ-cell tumors: natural history and pathogenesis. J Neurosurg. 1985;63:155-67.

6. Keene D, Johnston D, Strother D, Fryer C, Carret AS, Crooks B, et al. "Epidemiological survey of central nervous system germ cell tumors in Canadian children”. J. Neurooncol. 2007;82(3):289-95.

7. Srinivasan N, Pakala A, Mukkamalla C, Oswal A. Pineal Germinoma. South Med J. 2010;103(10): 1031-7.

8. Reisch N, Kühne-Eversmann L, Franke D, Beuschlein F, Mueller-Lisse UG, Reincke M, et al. Intracranial germinoma as a very rare cause of panhypopituitarism in a 23-year old man. Exp Clin Endocrinol Diabetes. 2009;117:320-3.

9. Reddy AT, Wellons JC III, Allen JC, Fiveash JB, Abadullatif $\mathrm{H}$. Refining the staging evaluation of pineal region germinoma using neuroendoscopy and the presence of preoperative diabetes insipidus. Neuro Oncol. 2004;6:127-33.

10. Ahmed SR, Shalet SM, Price DA, Pearson D. Human chorionic gonadotrophin secreting pineal germinoma and precocious puberty. Arch Dis Child. 1983;58:743-5.

11. Laidler P, Pounder DJ. Pineal germinoma with syncytiotrophoblastic giant cells: a case with panhypopituitarism and isosexual pseudopuberty. Hum Pathol. 1984;15:285-7.

12. Chao CK, Lee ST, Lin FJ, Tang SG, Leung WM. A multivariate analysis of prognostic factors in management of pineal tumor. Int J Radiat Oncol Biol Phys. 1993;27:1185-91.

13. Wong TT, Yen SH, Ho DM, Chang FC, Chang KP. Pineal germinoma with intratumoral hemorrhage after neuroendoscopic tumor biopsy. Childs Nerv Syst. 2003;19:769-72.

14. Devkota J, Brooks BS, el Gammal. Ventriculoperitoneal shunt metastasis of a pineal germinoma. Comput Radiol 1984;8:141-5.

15. Sawamura Y, de Tribolet N, Ishii N, Abe H. Management of primary intracranial germinomas: diagnostic surgery or radical resection? J Neurosurg. 1997;87(2):262-6.

16. Baehring J, Vives K, Duncan C, Piepmeier J, Bannykyh S. Tumors of the posterior third ventricle and pineal region: ependymoma and germinoma. J Neurooncol. 2004;70(2):273-4.

17. Al-Holou WN, Terman SW, Kilburg C, Garton HJ, Muraszko KM, Chandler WF. Prevalence and natural history of pineal cysts in adults. J Neurosurg. 2011;115(6):1106-14.

18. Ueba T, Yamashita K, Fujisawa I, Nakao S, Ooyama K, Yurihuji T, Kato SF, Seto S, Kageyama N. Long-term follow-up of 5 patients with intracranial germinoma initially treated by chemotherapy alone. Acta neurochirurgica 2007;149(9):897-902; discussion 902.

19. Packer RJ, Cohen BH, Cooney K, Coney K. Intracranial germ cell tumors. Oncologist 2000; 5(4): $312-20$

20. Calaminus G, Bamberg $M$, Jürgens $H$, Kortmann RD, Sörensen N, Wiestler OD. Impact of surgery, chemotherapy and irradiation on long term outcome of intracranial malignant non-germinomatous germ cell tumors: results of the German Cooperative Trial MAKEI 89. Klin Padiatr. 2004;216(3):141-9. 